\title{
Paisagem Sonora Urbana: escutas de Belo Horizonte
}

\section{Urban Soundscape: multiple listenings of Belo Horizonte}

\author{
Graziela Mello Vianna* \\ grazielamv@fafich.ufmg.br
}

\section{Resumo}

O presente artigo apresenta os resultados parciais do nosso projeto de pesquisa que observa a paisagem sonora urbana em constante transformação a partir do relato de ouvintes-cronistas- flaneurs e habitantes anônimos sobre a paisagem sonora da Belo Horizonte descritas em crônicas e depoimentos e também de registros fotográficos da cidade. Desenvolvemos uma pesquisa bibliográfica e documental e pretendemos ainda realizar atividades extensionistas relacionadas ao registro dos sons da cidade de Belo Horizonte e de depoimentos dos seus habitantes e disponibilizar o acervo à comunidade local. Sons esses que constituem a paisagem sonora urbana registrada em crônicas publicadas ao longo do século XX e presentes na memória afetiva daqueles que atualmente habitam a cidade.

Palavras-chave: Paisagem sonora urbana; flanêur, Memória.

\begin{abstract}
This paper presents partial results of our research project that looks at the urban soundscape and its constantly changing observed in literary texts written by listeners-flâneurs and anonymous people. We are considering chronicles and testimonies and also photos of the city made in the twentieth century. We developed a bibliographic and documentary research and we also intend to record the sounds of the city of Belo Horizonte and testimonies of its inhabitants. After this recording work, the files will be available to the local community. We believe that those sounds constitute the urban soundscape and they are part of the affective memory of those who currently inhabit the city.
\end{abstract}

Keywords: Urban soundscape; Flanêur; Memories.

* Doutora em Comunicação pela ECA/USP. Professora adjunta do Departamento de Comunicação da UFMG, onde coordena o grupo de pesquisa e extensão GRISsom, 
Artigos

\section{Apresentação}

A história de Belo Horizonte está nos documentos oficiais e mapas da cidade, mas também na memória e nos escritos de pessoas que vivenciaram as transformações pelas quais a cidade passou. Mudanças como o fim dos bondes, os sons das ruas, músicas que tocavam nas rádios e vitrolas, a construção de prédios comerciais e outras tantas ocorridas no espaço urbano são registradas por cronistas que flanam pela cidade em épocas distintas, tais como Cyro dos Anjos, Carlos Drummond de Andrade, Fernando Sabino, dentre outros, e permanecem na memória de seu habitantes. Espaço esse constituído pelas estruturas impostas pela arquitetura e pela topografia, mas também por elementos sonoros e visuais dinâmicos que se relacionam com as práticas sociais de seus habitantes. Em passagens da década de 1930, o autor Cyro dos Anjos ${ }^{1}$ e Carlos Drummond de Andrade (utilizando o pseudônimo de Antônio Crispim) registram alguns desses elementos que constituem paisagem da capital:

Éramos quatro ou cinco, em torno de pequena mesa de ferro, no bar do Parque (Municipal). Alegre véspera de Natal! As mulatas iam e vinham, com requebros, sorrindo dengosamente para os soldados do Regimento de Cavalaria. No caramanchão, outras dançavam maxixe com pretos reforçados, enquanto um cabra gordo, de melenas, fazia a vitrola funcionar. (ANJOS, 2002, p.21)

\footnotetext{
- V. não está seguindo o curso de desenho de Mme. Artus?

- Ainda é possível matricular-se no curso de desenho de Mme. Artus?

- Que pena eu não ser professora para poder frequentar o curso de Mme. Artus!

São pedaços de diálogos ouvidos no bonde, na Avenida Afonso Pena larguíssima e clara com as árvores cortadas, nas sorveterias e na sala de espera do Glória. (CRISPIM, 1930, p.9)
}

Passagens como estas de Cyro dos Anjos e de Carlos Drummond de Andrade nos provocam algumas inquietações. Qual a relação entre os sons de um ambiente e as pessoas que o habitam? Podemos relacionar as transformações da cidade e da paisagem sonora com as transformações nas relações de sociabilidade de seus habitantes? Como certos dispositivos sonoros alteram a paisagem sonora urbana? Como os relatos sobre a cidade nos dão a ver a tessitura dos relevos sonoros da paisagem? Imagens da cidade também nos permitiriam “ouvir" esses relevos a partir da representação de seus objetos e dispositivos sonoros?

Portanto, partindo dessas inquietações observamos essa paisagem dinâmica em constante transformação a partir do relato de ouvintes-cronistas- flanêurs sobre a paisagem sonora da cidade e, em seguida, de registros fotográficos da cidade descrita nas crônicas e de depoimentos dos seus habitantes sobre esses lugares. As proposições do pesquisador canadense Murray Schafer (2001) acerca da paisagem sonora ${ }^{2}$ mundial são norteadoras do nosso atual projeto de pesquisa e extensão intitulado Paisagem Sonora Urbana: escutas de Belo Horizonte vinculado ao grupo de pesquisa e extensão que coordenamos - GRISsom - no âmbito do departamento de Comunicação Social da UFMG.

Schafer (2001) considera como paisagem sonora "qualquer porção do ambiente sonoro vista como um campo de estudos. O termo pode referir-se a ambientes reais ou a construções abstratas como a composição musical" (SCHAFER, 2001, p.366). Para realizar a sua pesquisa sobre a paisagem sonora mundial, Schafer parte da leitura atenta de textos literários, textos jornalísticos e documentos oficiais onde são destacadas referências dos autores à paisagem sonora - desde os sons dos lugares em tempos remotos às transformações dos ruídos das cidades com a Revolução Industrial - para finalmente fazer um registro das paisagens sonoras contemporâneas e propor um projeto acústico mundial.

Não temos a pretensão de realizar um trabalho de tamanho escopo como a pesquisa de Schafer em um nível mundial e nem mesmo propor soluções para a poluição sonora nos centros urbanos como fez o autor. Utilizamos a metodologia do pesquisador para pensar apenas nas transformações (e implicações dessas transformações) de uma cidade relativamente jovem: Belo Horizonte.

Sendo assim, de acordo com as etapas do projeto detalhadas adiante neste artigo, trabalhamos com

1 Trecho do romance Amanuense Belmiro - criado a partir de crônicas de Cyro dos Anjos no jornal A Tribuna acerca da cidade de Belo Horizonte.

2 Tradução para o português do termo original em inglês - soundscape, derivado de landscape - utilizado pelo pesquisador. 
textos de cronistas que fazem referência à paisagem sonora, com imagens fotográficas de objetos sonoros que constituem a paisagem e com o registro da memória afetiva de seus habitantes por meio de relatos que possam nos desvelar as transformações ocorridas nesse espaço urbano planejado há pouco mais de um século. Dessa forma, inicialmente selecionamos textos e imagens que dão a ver as transformações do ambiente rural em cidade nos primeiros anos do século XX, a chegada das vitrolas e do rádio a partir da década de 1920 e dos dispositivos sonoros portáteis (desde o radinho de pilha na década de 70 aos Ipods nos anos 2000), as transformações nos transportes - dos bondes ao posterior desaparecimento dos mesmos com a chegada dos ônibus, a verticalização da cidade e as festas populares. Entendemos que tais transformações nos permitem observar permanências e alterações na paisagem sonora da cidade e também podem ser indicadores privilegiados das práticas sociais dos indivíduos que habitam o espaço urbano. Ao longo do desenvolvimento do projeto, outros aspectos significativos das transformações do espaço urbano podem surgir e serem incorporados ao recorte inicial. Interessa-nos as vivências cotidianas na cidade, a partir do olhar e da escuta de quem a observa.

Consideramos a memória afetiva dos habitantes de uma cidade como fonte, uma vez que esses habitantes fazem parte da tessitura das relações de sociabilidade que constituem a vida cotidiana na cidade. Pretendemos assim registrar a memória sobre lugares da paisagem urbana permite que os habitantes se reconheçam nesses registros pessoais da cidade que evidenciam práticas cotidianas relacionadas a esses lugares que nem sempre se dá a ver em registros oficiais. Os resultados do projeto podem ainda servir como fonte para investigações futuras sobre a cidade.

\section{Flanando pelas ruas da cidade de Belo Horizonte}

Benjamim afirma que "a cidade é o autêntico chão sagrado da flanêurie” (1994, p.191), e que o "fenômeno da banalização do espaço" constitui-se em experiência fundamental para o flanêur (1994, p.188), enquanto Baudelaire (2001) considerava a cidade sedutora, uma vez que as ruas labirínticas da cidade constituem o fascínio da multiplicidade e do efêmero, o gosto pelo movimento ondulante da multidão para o "perfeito divagador" ou "observador apaixonado", afinal "aquilo a que homens chamam amor é coisa bem pequena, restrita e frágil, se comparável a essa inefável orgia, a essa santa prostituição da alma que se entrega por inteiro, poesia e caridade, ao imprevisto que surge, ao desconhecido que passa (BAUDELAIRE apud BENJAMIN, 2009, p.480).”

Considerando, portanto, o cronista como o flanêur de Baudelaire que vaga e observa apaixonadamente a cidade, fizemos a escolha de utilizar crônicas literárias sobre a cidade como parte do material empírico de pesquisa, uma vez que não nos interessa o texto factual que relata o acontecimento e sim os relatos que se deixam conduzir pela "alma encantadora das ruas" (RIO, 2008) e, assim, nos dão a ver/ouvir elementos que constituem o cotidiano e a paisagem em constante transformação da cidade.

Ao flanar pela cidade, percebemos marcas dessa transformação, marcas do tempo, "uma vez que os elementos temporais mais heterogêneos coexistem, portanto, na cidade (...). "Quem entra em uma cidade sente-se como em um tecido de sonho, onde um acontecimento de hoje se articula com o mais remoto (LION apud BENJAMIN, 2009, p.478/479)." Mesmo em uma cidade jovem como Belo Horizonte, estas marcas se fazem presentes. Podemos, por exemplo, ao caminhar por uma rua, entrar em uma pequena casa do período eclético do início do século e em seguida em um edifício alto construído nos anos 2000 com uma profusão de vidros verdes, mármores e "espaços gourmet", tal como regem os atuais modismos locais na arquitetura. Ambos são registros de fragmentos das vivências cotidianas em tempos distintos.

Nem confissões, mergulhos subjetivos, nem ensaios clássicos, as paisagens articuladoras de imagens e conceitos, são marcas de um sujeito feito de exterioridades, de um texto de superfícies. A paisagem é mais do que um estilo de pensar e escrever, é uma forma de viver à deriva. (LOPES, 2006, p.133)

Para além das marcas do tempo percebidas pela arquitetura, o relato do flanêur também nos permite perceber no espaço urbano contemporâneo, rastros do tempo, pois, concordando com Benjamin, em uma de suas Passagens, 
Artigos

a rua conduz o flâneur em direção a um tempo que desapareceu. Para ele, qualquer rua é íngreme. Ela vai descendo, quando não em direção às mães, pelo menos rumo a um passado que pode ser tão mais enfeitiçante por não se o seu próprio passado, seu passado particular. Entretanto, este permanece sempre o tempo de uma infância. Mas porque o tempo de sua vida vivida? No asfalto sobre o qual caminha, seus passos despertam uma surpreendente ressonância. A iluminação a gás que recai sobre o calçamento lança uma luz ambígua sobre este duplo chão. (2009, p.461)

Em um trabalho anterior ${ }^{3}$, apresentamos uma primeira experiência de escuta de três personagens que habitam o centro da cidade e flanam pela região. Foram eles: Baiana, a pipoqueira; Maria, a catadora de papel e Maninho, o engraxate. Em seus relatos, esses personagens contam histórias de quem passou grande parte da juventude trabalhando e constituindo a paisagem urbana de Belo Horizonte. Eles que fizeram e fazem da capital cenário de vida trazem em suas falas as lembranças de um tempo que já passou, mas que ainda reside em suas memórias. A percepção dos personagens sobre a cidade se faz presente em relatos não trazem as mesmas informações que estão registradas nos livros, já que cada pessoa realiza uma leitura própria sobre a realidade, uma vez que a constituição da memória é da ordem do fragmentado, do descontínuo, o que traduz a impossibilidade de alcançar um sentido único para os acontecimentos. De acordo com Paul Ricoeur (2007), a memória é uma forma de ter acesso a um passado ausente no presente. A memória não deve ser pensada como uma entidade isolada, com existência própria, e sim como algo fruto de um constante embate entre diversos tipos de fontes de informação. Há, portanto, inesgotáveis maneiras de vislumbrar a memória da cidade e a escolhida aqui foi por meio pequenos recortes da paisagem trazidos ao presente, (re) significando características da cidade.

$\mathrm{Na}$ pesquisa que desenvolvemos atualmente privilegiamos nessa paisagem a escuta dos elementos sonoros que a constituem por entendermos que tais elementos tem o poder de evocar lembranças multisensoriais, como defende Haye (2004, p. 45),

O estímulo acústico de possibilitar esse caráter (multisensorial) mediante sua enorme capacidade evocadora e criadora permite que se desdobre o princípio de visibilidade por meio do qual sujeitos, objetos, situações e cenários são 'mostrados' à imaginação do ouvinte. [...] Assim, o som seduz a visão, o paladar e o olfato dos ouvintes transmitindo a aspereza do tronco da árvore, a suave coloração do poente ou a excitante fragrância do guisado sendo cozido na velha panela de pressão queimada da avó.

Assim, a escolha pela reflexão sobre as textualidades sonoras que afloram nas crônicas sobre a cidade e nos depoimentos de seus habitantes se relaciona com esse caráter multisensorial dos elementos sonoros. Elementos esses que constituem um texto unisensorial, mas que evocam vários sentidos da percepção, tornando-se assim um profícuo objeto de análise.

Pretendemos, em uma etapa futura do desenvolvimento do projeto de pesquisa, cotejar tais textualidades sonoras com registros fotográficos da cidade a fim de perceber as relações da memória afetiva dos habitantes da cidade - acionada a partir dos elementos sonoros que constituem a paisagem - com as imagens que também a constituem. Entendemos que tal esforço nos permitirá compreender a multisensorialidade da paisagem urbana.

\section{Paisagens sonoras dinâmicas}

Conforme já mencionamos, a metodologia de pesquisa de Murray Schafer (2001) acerca das paisagens sonoras mundiais é norteadora do nosso trabalho. Mas também consideramos trabalhos de pesquisadores como Massimo di Felice (2009), Pierre Schæffer (1970), Haye (2004) e Balsebre (1996) como contribuições importantes para a nossa pesquisa.

Além de observar as paisagens sonoras desde relatos da Antiguidade até o tempo presente, Murray Schafer (2001) faz um esforço de estabelecer uma tipologia das paisagens e classificar os elementos que a constituem.

3 Trabalho intitulado Vozes da Cidade apresentado no GP Rádio e Mídia Sonora do XIII Encontro dos Grupos de Pesquisa em Comunicação, evento componente do XXXVI Congresso Brasileiro de Ciências da Comunicação ocorrido em setembro de 2013 na cidade de Manaus. 
Ele estabelece dois principais tipos de paisagem. O primeiro tipo seria a paisagem $h i-f i$ onde se pode distinguir os elementos sonoros com clareza. Um exemplo desse tipo de paisagem é o ambiente rural quando percebemos os pássaros, o mugir de uma vaca, o coachar dos sapos situados em diversos planos sonoros. Outro tipo de paisagem surge com o crescimento das cidades: a paisagem lo-fi onde os sons sobrepostos constituem uma massa sonora em que não conseguimos distinguir os elementos sonoros, como acontece nos hipercentros das grandes cidades. As paisagens sonoras hi-fi se tornam a cada dia mais raras nas metrópoles.

Acompanhamos como essa transformação se dá em uma cidade como Belo Horizonte, uma cidade planejada e edificada em poucos anos em uma região originalmente rural: o Curral Del Rey. Acreditamos que as crônicas, os registros fotográficos e os relatos de habitantes que acompanharam parte das transformações nos desvelam aspectos interessantes da paisagem predominantemente $h i-f i$ transformada de forma acelerada em uma paisagem lo-fi em algumas regiões.

Além de estabelecer uma tipologia das paisagens sonoras, Schafer faz um esforço de classificar os elementos que as constituem. Dessa forma, Schafer (2001) classifica esses elementos como sons fundamentais, sinais e marca sonora, que consideramos como "relevos" da paisagem.

Os sons fundamentais são aqueles que, de tão integrados ao nosso cotidiano, não prestamos muita atenção neles, ou melhor, seriam os sons que não precisam ser ouvidos conscientemente, se tornam hábitos auditivos, tais como o mar, os insetos, os carros, os antigos bondes, os ônibus.

Os sinais sonoros são os sons que, apesar de cotidianos, são destacados dentre os sons fundamentais e precisam ser ouvidos conscientemente, pois funcionam como um aviso acústico como, por exemplo, o apito do guarda de trânsito ou a sirene de uma ambulância. (SCHAFER, 2001). As buzinas dos carros e ônibus são exemplos de sinais sonoros que fazem parte das paisagens sonoras contemporâneas. Na Praça da Rodoviária no centro de Belo Horizonte, por exemplo, registramos o som da voz de vendedores que anunciam com insistência transporte alternativo para cidades vizinhas à capital. Tais sons podem ser considerados como um sinal sonoro, pela função prática de vender e informar sobre o transporte alternativo ou ainda uma marca sonora característica daquela região. Schafer (2001, p.27) define marca sonora como um "som da comunidade que seja único ou que possua determinadas qualidades que o tornem especialmente significativo ou notado pelo povo daquele lugar".

Entendemos que tais definições de Schafer são tentativas de sistematizar os elementos da paisagem sonora. No entanto, acreditamos que os limites dessa classificação devem ser fluidos, no sentido de que um som pode ser classificado em mais de uma dessas três categorias, dependendo do lugar em que se situa o ouvinte, se ele habita aquele lugar, se é um "ouvinte-estrangeiro", por exemplo. Pensando ainda na fala daqueles que anunciam o transporte, tais sons podem ser considerados, como argumentamos anteriormente, como sinais sonoros, para quem tem interesse pelo transporte alternativo, mas também como marca sonora para quem não frequenta a região com regularidade e para quem percebe a singularidade daqueles sons. $\mathrm{E}$ ainda podem ser considerados como sons fundamentais se tomamos como referência a escuta de quem habita a região e por ouvir com tanta frequência tais sons já não os ouve conscientemente. Para este, o anúncio "sete Lagoas, Sete Lagoas..." ou "Ouro Preto, Ouro Preto.." se mistura a outros sons que compõem a massa sonora desse ambiente lo-fi. Consideramos assim a paisagem sonora como dinâmica, que se transforma cotidianamente e na qual o ouvinte tem um papel determinante.

Podemos citar como outro exemplo dessa dinamicidade um dos sons registrados durante as entrevistas com Maria, que trabalha durante a madrugada - os sons emitidos por ratos. Sons esses que ouvimos na rua Curitiba, em frente a Galeria do Ouvidor, tradicional edifício comercial, localizado no centro de Belo Horizonte. O som dos ratos que, para nós que muito raramente passamos naquela rua de madrugada, portanto "ouvidos estrangeiros" naquela paisagem, identificamos como uma marca sonora daquele lugar. Uma característica inerente ao local é a grande quantidade de roedores que saem dos bueiros e transitam pelas ruas emitindo um ruído bem característico. Além dos ratos, é possível também ouvir os morcegos. Esses mamíferos ficam escondidos no ponto mais alto das árvores. Para Maria, o som desses animais é um som fundamental, ela já nem os ouve, mas para quem não tem costume de passar pelo centro de madrugada pode ser compreendido como uma marca sonora. Tal marca sonora pode ser considerada para nós, "ouvidos- estrangeiros" como característica do centro à noite, pois pode ser ouvida exclusivamente quando escurece e o número de pessoas que transitam pelo Centro diminui. 
Artigos

Concordamos com Marra e Garcia (2012, p. 46) quando defendem que "podemos pensar a sonoridade urbana com este grau de interação comunicativa: a sonoridade seria formada pela interação dos sons existentes em determinado espaço, percebidos pela audição de seus habitantes; ao mesmo tempo, são os habitantes que produzem a diversidade de sons". Baiana, a pipoqueira (que mencionamos anteriormente), é um exemplo. Ela, ao mesmo tempo, habita a paisagem do centro de Belo Horizonte e a altera com ruídos que produz ao exercer o seu ofício de fazer pipoca.

No entanto, apesar de abandonarmos esse exercício taxionômico de Schafer no sentido de delimitar com certa rigidez esse "relevo" das paisagens sonoras, concordamos com o autor quando ele afirma que " o ambiente acústico geral de uma sociedade pode ser lido como um indicador das condições sociais que o produzem e nos contar muita coisa a respeito das tendências e da evolução dessa sociedade" (idem, p.23). Dessa forma, pretendemos tanto fazer o registro desses sons existentes no espaço, dos sons produzidos por aqueles que habitam esses espaços, mas também nos guiaremos pela escuta dos habitantes registradas em crônicas ao longo das décadas e pelos relatos de habitantes que registraremos ao longo do projeto.

Ainda tomando como exemplo, uma das três personagens mencionadas, Maria, ao falar das lembranças que tem do bonde, tenta imitar com a boca o ruído que o veículo fazia ao passar pelos trilhos. Ela chega a comparar os sons com os feitos pelo trem. Ao tentar reproduzir o barulho com os lábios, Maria se permite rememorar a paisagem urbana da cidade no passado. Com isso, nos sugere a pensar sobre as transformações na paisagem sonora urbana.

Maria: Ah, não tem nem como te explicar ele era tipo um trenzinho! Você já viu aquele trenzinho que fica levando criança no Parque Municipal? Ele era daquele tipo. o tempo do bonde que era bom! Nós era muito molecado. Hoje em dia, cruz credo! Eles deveriam trazer o bonde de novo! (...) o barulho do trem era assim :[Maria reproduz com os lábios os sons do bonde e o barulho que fazia nos trilhos].

A imitação feita por Maria é fruto de uma rememoração de um som que pertencia à paisagem urbana da cidade e que já não existe mais. Era um som fundamental (SCHAFER, 2001) da paisagem sonora daquele tempo, pois o ruído dos bondes prevalecia nas principais avenidas, como a Afonso Pena. Atualmente, percebemos ao invés do ruído dos motores dos automóveis, as buzinas, os alto-falantes das lojas, os locutores com seus microfones, anunciando os produtos.

Se por um lado, Maria rememora o som dos bondes, Maninho relata que nos anos 60, o que prevalecia no centro da capital, principalmente na rua dos Carijós, era o som dos pássaros de dia e das cigarras à noite:

Maninho: O que tinha muito era muitas árvores e cigarras na rua Carijós com a São Paulo. Quando ia escurecendo era uma cantaria. Era uma noite tranqüila que não tinha tanto barulho e som dos carros que era mais lentamente. Não era como hoje! Tinha também muitos passarinhos que você ficava encantado com o som deles. A cigarra era o nosso divertimento! Uma cantava de um lado, a outra cantava de outro! Era um som alegre, sentíamos muito felizes de ouvir. Hoje, não tem mais isso! Não vemos mais passarinhos no centro. Nós gostávamos também de pegar borboletas!

Pensando nessa colocação de Maninho, os sons dos pássaros durante o dia e das cigarras à noite podem ser classificados como sons fundamentais, pois estavam imbricados na paisagem urbana dos anos 60, período em que, como dito, era comum ouvir o predomínio do canto dos pássaros em relação aos sons dos carros. Hoje, como lembrou Maninho, não se ouve pássaros no centro da capital mineira. Pombos são vistos, mas os pássaros que cantavam antigamente, não.

No sentido de refletir sobre a vida cotidiana dos habitantes de uma cidade tecida na paisagem urbana dessa cidade, consideramos relevantes as proposições de Massimo Di Felice (2009), sociólogo e pesquisador de novas tecnologias comunicativas, ao tratar das paisagens contemporâneas - que ele denomina como "paisagens pós-urbanas" e as relações com os sujeitos que as habitam. O próprio autor define o seu trabalho da seguinte forma:

Superando as percepções arquitetônicas e topográficas, propomos uma interpretação teórica midiática e comparativa do habitar, aprofundando os seus possíveis significados a partir das interações e das articulações que mídia, sujeito e território passam a desenvolver entre si, em épocas tecnológicas diferentes e no interior de distintas arquiteturas comunicativas. (2009, p.20) 
Entendemos as paisagens sonoras urbanas como lugares dinâmicos constituídos pela presença do ouvinte como sujeito e pelos inúmeros dispositivos que atravessam a sua tessitura. Maninho, um dos nossos personagens mencionados, nos conta em seus relatos que o rádio era um objeto "inseparável" do seu cotidiano, funcionando principalmente, segundo Maninho, como meio de comunicação popular entre os engraxates do centro de Belo Horizonte.

\begin{abstract}
Maninho: o rádio faz parte da nossa vida, das coisas que não era tão fácil, mas todo mundo tinha. Quando dormia ligava o radio para dormir mais o rádio. Era meu companheiro desde a infância até hoje! A televisão chegou logo depois, mas o rádio é o rádio! Desde que trabalhávamos tinha um amigo, que já faleceu, o Gilberto, ele colocava na Rádio Cultura. De duas da tarde às quatro, ouvíamos. No período da manhã era Roberto Carlos, a tarde era algo mais parecido com o rock, a noite, o ritmo da noite, isso tocava nosso coração. Na época, éramos uns 10 engraxates juntos e conseguimos três caixas de som e ficamos trabalhando e ouvindo o rádio. Tinha momentos que até dançávamos!
\end{abstract}

Se o aparelho era apropriado como "companheiro" de trabalho, ele também era imprescindível na vida noturna. Os lugares frequentados pelos personagens são marcados também pelos sons do "momento" transmitidos pelas ondas radiofônicas. Baiana, Maria e Maninho também compartilharam durante os seus relatos, os lugares em que saíam para se divertir, as canções que ouviam e também as características das vestimentas das pessoas que saíam à noite para dançar. Maninho e Baiana, por exemplo, se divertiam muito na noite na capital mineira.

Baiana: Eu ia muito no Elite, na Bia Fortes era só tango e falsa valsa que tinha lá. Coisa boa! Ia só rico lá! Aqueles velhos do café Nice ia tudo lá! Agora, acabou o Elite, acabou! Já dancei muita gafieira. O Elite era o melhor lugar que tinha para dançar. Eu largava serviço no casarão e ia com as amigas. Lá era bom demais. Eu gostava de dançar tango. Usava aqueles vestidinhos coladinhos. Naquela época eu podia, né? Eu era magrinha. Hoje eu estou um botijão! Lá tocava músicas em cada bloco.

Portanto, além dos dispositivos midiáticos, nos interessam também os objetos sonoros que fazem parte da paisagem. Pierre Schæffer (1970) denomina "objeto sonoro " a unidade sonora capaz de sugerir sentido. Chion, define o conceito de "objeto sonoro" mais precisamente como

uma unidade sonora percebida na sua matéria, na sua textura própria, nas suas qualidades e nas suas próprias dimensões perceptivas. Além disso, o objeto sonoro representa uma percepção global que se dá de forma idêntica por meio de diferentes escutas, um conjunto organizado que se pode assimilar a uma gestalt no sentido da psicologia da forma. (CHION, 1983, p. 34) ${ }^{4}$

Assim, podemos dizer que o objeto sonoro é constituído de elementos sonoros, mas sua unidade e sua possibilidade de sugerir uma imagem para o ouvinte é que o definem como tal. Sabemos mesmo sem enxergá-lo, o tamanho do cachorro que late do lado de fora da casa. Tal latido seria, de acordo com Schæffer (1970) , um objeto sonoro que nos sugere a imagem do cachorro. No presente projeto, pretendemos trabalhar tanto com registros sonoros dos objetos quanto com as imagens relacionadas aos mesmos, a fim de refletir sobre aspectos da multisensorialidade evocada por tais objetos sonoros que constituem a paisagem sonora urbana.

Explicitaremos, a seguir, a metodologia do projeto e as etapas desenvolvidas a fim de buscar responder às nossas inquietações sobre a paisagem urbana e os elementos que a constituem.

\title{
Etapas da pesquisa
}

Para dar conta das proposições aqui delineadas, realizamos inicialmente uma pesquisa bibliográfica acerca de pesquisas que tem a paisagem urbana como objeto. Em seguida, desenvolvemos uma pesquisa documental a fim de elencar crônicas de autores que viveram em Belo Horizonte que mencionam a paisagem sonora da cidade. As principais fontes dessa pesquisa são os arquivos de jornais e periódicos de Belo

4 Tradução nossa 
Artigos

Horizonte, o Arquivo Público Mineiro e coletâneas de crônicas publicadas em livros. Tal pesquisa tem a participação dos bolsistas vinculados ao GRISsom e ainda de alunos de graduação em Comunicação Social da UFMG que cursam a Oficina Som e Sentido.

Foram consideradas as referências à paisagem mencionadas anteriormente. Inicialmente seriam estas: as transformações do ambiente rural em cidade nos primeiros anos do século XX; os dispositivos e objetos sonoros; os transportes; a verticalização da cidade e as festas populares. No entanto, essa pesquisa documental ainda está em andamento e com o decorrer do seu desenvolvimento podem surgir referências a outros tipos de transformações que, caso sejam recorrentes, podem ser acrescentadas ao recorte inicial.

Quando finalizarmos a pesquisa documental, serão selecionados os lugares da cidade recorrentes nas crônicas. A partir da seleção desses lugares, será realizada uma pesquisa sobre registros fotográficos em cada década que evidenciam objetos sonoros.

Com a colaboração dos bolsistas e dos pesquisadores voluntários do GRISsom, será realizado também o registro sonoro e fotográfico atual dos lugares selecionados fazendo uso da estrutura laboratorial do departamento de Comunicação e dos equipamentos adquiridos com os recursos do CNPq, da FAPEMIG e da PRPq.

Faremos ainda um trabalho de registro do depoimento de moradores do entorno dos lugares selecionados, a fim de constituirmos um acervo também a partir da memória daqueles que habitam ou habitaram os lugares selecionados. Já fizemos algumas experiências nesse sentido, conforme mencionado anteriormente, mas pretendemos ter um volume maior de relatos, a fim de constituirmos um acervo significativo. Para tanto, selecionaremos depoentes voluntários, a partir de uma pesquisa no entorno dos lugares e uma chamada pública por meio de material de divulgação do projeto impresso e via redes sociais convidando os moradores a compartilhar suas lembranças acerca de tais lugares por meio do registro realizado para o projeto. Os relatos serão estimulados a partir da exibição aos moradores voluntários dos trechos que fazem menção à paisagem sonora dos lugares das crônicas selecionadas e dos registros sonoros e fotográficos de tais lugares. Assim, acreditamos que tais representações ativem um processo de rememoração dos entrevistados acerca dos lugares que constituem a paisagem urbana.

Dessa forma, buscaremos ver, ler e ouvir as lembranças acerca da paisagem sonora e cotejá-las com os registros atuais a fim de compreender as transformações ocorridas na paisagem e nas relações de sociabilidade na cidade.

Ao final do projeto, a fim de disponibilizar os diversos registros da paisagem urbana para a comunidade local e ainda dar visibilidade ao projeto, pretendemos realizar uma exposição com o material sonoro e com o registro fotográfico. Em tal exposição, prevemos instalações sonoras com os registros sonoros realizados, exibição das fotografias levantadas na pesquisa e dos novos registros realizados ao longo do projeto, cabines para escuta da paisagem sonora de Belo Horizonte e cabines para registro de novos depoimentos dos visitantes da exposição sobre os lugares exibidos, a fim de ampliar o diálogo com a comunidade local. O local da exposição ainda será definido no decorrer do desenvolvimento do projeto, mas inicialmente pensamos em espaços que contribuem para a compreensão da dinâmica sócio-histórica da cidade, como por exemplo, o Museu Histórico Abílio Barreto ou o Museu de Artes e Ofícios, a fim de relacionar os registros do projeto proposto com os acervos de espaços como esses. Acervos cujos elementos constituintes podem ser considerados como indicadores das transformações ocorridas ao longo das décadas em Belo Horizonte e na vida cotidiana de quem a habita.

Pretendemos ainda organizar uma publicação multimídia, mais precisamente um livro acompanhado de um DVD com os resultados do projeto, e desenvolver um website para acesso livre da comunidade, de pesquisadores, estudantes e visitantes da cidade.

No website, além de informações sobre o projeto, pretendemos disponibilizar um aplicativo por meio do qual aquele que o acessa, ao utilizar algum dispositivo que possua geolocalização (tais como smartphones ou GPS), possa flanar pela cidade guiado por um mapa interativo com a marcação dos lugares selecionados. Nessas marcações, estarão disponíveis os resultados específicos daquele lugar: as crônicas que o mencionam, os registros sonoros e fotográficos, os depoimentos de moradores e um resumo das reflexões sobre as transformações da paisagem. Consideramos tais formas de disponibilização dos resultados como um meio de aproximação entre a pesquisa acadêmica e a comunidade local. 
Prevemos ainda uma avaliação do impacto do projeto para a comunidade local por meio de questionários a serem preenchidos pelos visitantes da exposição, do website e pelos utilizadores do aplicativo.

\section{Considerações finais}

A memória coletiva (ou social) não tem uma forma permanente. Ela é negociada no corpo social de crenças e valores, rituais e instituições. Nossa vontade presente tem grande impacto sobre o que e como rememoramos.

O passado rememorado está sempre inscrito no nosso presente. Toda a estrutura de memória é fortemente contingente frente à formação social que a produz. Nossa memória é construída através de uma variedade de discursos e diversas camadas de representações.

Assim, além da pesquisa documental que realizamos acerca das crônicas sobre a cidade que se configuram como relatos de habitantes ou visitantes sobre a cidade, propomos ouvir quem habita a cidade nos dias atuais, buscando assim registrar a memória afetiva desses habitantes acerca da paisagem urbana. O cenário urbano de Belo Horizonte de 40 anos atrás desperta saudades em Baiana, Maria e Maninho como "um tempo bom que não volta mais", personagens que habitam e constituem a paisagem sonora urbana desde a década de 50.

Pretendemos também constituir um lugar de memória da cidade, ao disponibilizar à comunidade um acervo com os resultados da pesquisa, os registros sonoros e fotográficos da paisagem urbana e os depoimentos coletados.

Por outro lado, o projeto contribui para a formação dos pesquisadores e dos alunos envolvidos ao ampliar a reflexão crítica dos mesmos acerca da paisagem urbana ao se considerar como fontes de pesquisa outras além dos registros oficiais sobre a cidade, tais como: os sons que constituem a paisagem, os registros fotográficos e sobretudo, os saberes e a memória afetiva daqueles que habitam (ou habitaram) a paisagem urbana e fazem parte da tessitura das relações de sociabilidade que constituem as cidades, sejam eles cronistas consagrados ou moradores anônimos.

\section{Referências}

ANJOS, Cyro dos. O amanuense Belmiro. Belo Horizonte: Livraria Garnier, 2002.

BALSEBRE, Armand. El lenguaje radiofónico. Madrid: Cátedra, 1996.

BAUDELAIRE, Charles. O pintor da vida moderna. Sobre a modernidade. São Paulo: Paz e terra, 2001.

BENJAMIN, Walter . Obras escolbidas III: Charles Baudelaire um lírico no auge do capitalismo. 3a. ed. São Paulo: Brasiliense, 1994.

CHION, Michel. Guide des objets sonores. Pierre Schaeffer et la Reserche Musicale. Paris: INA-GRM/BUCHET, 1983.

CRISPIM, Antônio. Mme. Artus.In: Jornal Minas Gerais. Belo Horizonte, 06 abril.1930.

DI FELICE, Massimo. Paisagens pós-urbanas: o fim da experiência urbana e as formas comunicativas do habitar. São Paulo: Annablume, 2009.

HAYE, Ricardo. El arte radiofónico: algunas pistas sobre la constitución de su expresividad. Buenos Aires: LaCrujia, 2004.

LOPES, Denilson. Paisagens da cultura, paisagens sonoras. In : FREIRE FILHO, João ; JANOT'TI JUNIOR, Jeder. Comunicação e música popular massiva. Salvador :Edufba, 2006.

MARRA, P., GARCIA, L..Ouvir música na cidade: experiência auditiva na paisagem sonora urbana do hiper- 
Artigos

centro de Belo Horizonte. Contemporânea. Rio de janeiro: 10, nov. 2012. Disponível em: < http://www. epublicacoes.uerj.br/index.php/contemporanea/article/view/3178>. Acesso em: 08 Mar. 2014.

RICOEUR, Paul. A memória, a história, o esquecimento. Campinas, (SP): Editora UNICAMP, 2007.

RIO, João do. A alma encantadora das ruas. São Paulo: Companhia das Letras, 2008.

SCHAFER, R. Murray. A afinação do mundo: uma exploração pioneira pela história passada e pelo atual estado do mais negligenciado aspecto do nosso ambiente: a paisagem sonora. São Paulo: Editora UNESP, 2001.

SCHÆFFER, Pierre. Machines à communiquer I. Genèse des simulacres. Paris: Seuil, 1970. 